\title{
Interações discursivas em uma aula on-line de língua inglesa na plataforma Google Meet
}

\author{
Rafael Lira Gomes Bastos (UFC)* \\ https://orcid.org/0000-0002-6828-5976
}

\section{Resumo:}

Considerando o contexto do ensino remoto emergencial, o objetivo deste estudo é compreender as características das interações discursivas em uma aula on-line de língua inglesa na plataforma Google Meet. Os exemplos das interações são provenientes da gravação de uma aula da turma de semestre dois do curso de inglês do Centro Cearense de Idiomas, unidade Jóquei. Assumindo um olhar dialógico, as interações discursivas foram caracterizadas a partir do contexto de realização da aula e das atitudes ativo-responsivas dos interlocutores - professor e alunos - em função da construção de um projeto comunicativo no qual os alunos pudessem falar sobre acessórios e perguntar sobre preços em inglês. 0 estudo oferece, portanto, um panorama das características das interações discursivas em uma aula on-line de língua inglesa na plataforma Google Meet vinculadas às suas etapas de organização, comparando, sempre que possível, com a aula presencial.

Palavras-chave: Interação discursiva; Aula on-line de língua inglesa; Ensino remoto emergencial;

\section{Abstract:}

\section{The discursive interactions in an on-line English class on the Google Meet Platform}

Considering the context of the emergency remote teaching, the aim of this study is to understand the characteristics of the discursive interactions of an on-line English class on the Google Meet platform. The examples of interactions came from an English course semester two class recording at the Centro Cearense de Idiomas, Joquei center. Assuming a dialogic point of view, the discursive interactions were characterized considering the context of class realization and interlocutors' - teacher and students -active-responsive attitudes due to the construction of a communicative project in which students could talk about accessories and ask about prices in English. The study offers a panorama of discursive interaction characteristics in the on- 
line English class on the Google Meet platform connected to its organizational steps, comparing them to the face-to-face class when it was possible.

Keywords: Discursive interaction; English on-line class; Emergency remote teaching.

\section{Considerações iniciais}

Diante da necessidade de isolamento social provocada pela pandemia da covid-19, vários estados do Brasil passaram a adotar o que se tem denominado de ensino remoto emergencial. No estado do Ceará, por exemplo, a partir do mês de março de 2020, foi lançada uma diretriz ${ }^{1}$ que viabilizou esse modelo de ensino em toda a rede pública estadual da educação básica vinculada à Secretaria de Educação do Estado do Ceará (SEDUC-CE). Mesmo em contexto pandêmico e ainda com poucas informações sobre a gravidade da doença, a maioria das escolas decidiu pela continuidade do ano letivo. Da mesma forma, os Centros Cearenses de Idiomas (doravante, $\mathrm{CCI})^{2}$, local de minha atuação profissional, viram-se na obrigação de continuar suas atividades remotamente.

A repentina necessidade da adequação do ensino presencial para o remoto, sem discussão detalhada sobre como aconteceria essa mudança, gerou uma série de dificuldades. O CCI Jóquei, por exemplo, atende alunos que, muitas vezes, não têm acesso ao computador e/ou à internet de qualidade, o que tornou difícil o acompanhamento das interações síncronas e assíncronas demandadas pelo novo contexto de interação. Além

1 As diretrizes podem ser acessadas no seguinte link: https://www.seduc.ce.gov.br/wp-content/ uploads/sites/37/2020/03/diretrizes_escolas. pdf. Acesso em: 21 out 2020.

2 Os CCIs são centros de idiomas criados e mantidos pela Secretaria de Educação do Estado do Ceará (SEDUC-CE) com o objetivo de ofertar cursos livres de idiomas (inglês, espanhol e francês) para alunos e professores da rede pública da educação básica. dessa dificuldade, Paes e Freitas (2020), depois de pesquisa realizada com professores da rede pública estadual do Ceará, apontam que a falta de formação inicial e continuada de professores voltadas para o uso de tecnologias digitais, o excesso de trabalho docente e a ausência de uma política de inclusão digital para os alunos são os principais empecilhos para garantir a qualidade do ensino-aprendizagem em tempos pandêmicos. No caso específico do ensino da língua inglesa nos CCIs, excessos de atividades, atividades descontextualizadas e repetição de tarefas do livro didático na plataforma Google sala de aula foram apontados pelos alunos como alguns dos problemas enfrentados no primeiro semestre letivo de 2020.1 (cf. BASTOS; LIMA, 2020).

Com o passar do tempo e a mudança de semestre, no entanto, as reflexões do nosso coletivo de trabalho demandaram práticas mais reflexivas, ouvindo, sobretudo, o que os alunos tinham a dizer. Vencidos os desafios iniciais, o ensino remoto emergencial no CCI Jóquei, no semestre 2020.2, foi organizado semanalmente a partir da realização de uma aula assíncrona na plataforma Google sala de aula com a postagem de uma atividade via formulário Google e uma atividade lúdica (jogo on-line, música, vídeo etc.); e uma aula síncrona na plataforma Google Meet. Diante da demanda de uma aula síncrona, não é raro, nós professores, nos questionarmos sobre como interagir com os alunos durante uma aula on-line, uma vez que somos cientes de que a mudança do presencial para o 
remoto impacta as formas de interação, especialmente quando essa mudança se dá em contexto emergencial.

Por tudo isso, apresento este estudo com o objetivo de compreender as características das interações discursivas em uma aula on -line de língua inglesa na plataforma Google Meet. Para dar conta do objetivo, analiso as interações discursivas de uma aula da turma de semestre dois do curso de inglês do CCI, unidade Jóquei. Assumindo um olhar dialógico, as interações discursivas foram caracterizadas a partir do contexto de realização da aula e das atitudes ativo-responsivas dos interlocutores - professor e alunos - em função da construção de um projeto comunicativo no qual os alunos pudessem falar sobre acessórios e perguntar sobre preços em inglês, comparando, sempre que possível, com as interações da aula presencial. Parto do pressuposto de que o discurso e, consequentemente, as interações discursivas em uma sala de aula - presencial ou remota - é uma atividade situada em um determinado contexto sócio-histórico (BAKHTIN, 2016). Por isso, as interações discursivas são diversas, mas organizadas a partir de um repertório de fórmulas recorrentes e, na aula on-line, pelas condições sócio-históricas específicas em que estamos vivendo devido à pandemia da covid-19, assumem vicissitudes diferentes da aula presencial, apesar de manterem muitas semelhanças.

Ao fazer esse recorte para a pesquisa, não quero dizer que os problemas anteriormente mencionados foram resolvidos. As questões sobre o acesso dos alunos às tecnologias digitais e a formação do professor carecem de problematização, especialmente no escopo da Linguística Aplicada (LA) que pratico. Mas, por enquanto, os interesses que movem este trabalho partem desse lugar que ocupo, de professor de língua ingle- sa que interage semanalmente de forma on -line com seus alunos e enfrenta o desafio do ensino remoto emergencial. Isto quer dizer que, em minha pesquisa, o ponto de partida é o reconhecimento da minha própria participação no existir-evento de minha vida, na união do mundo da cultura (pesquisa) com o mundo da vida (aula), para usar as palavras de Bakhtin (2017). 0 que trago para a discussão, contudo, é apenas uma possibilidade de reflexão a partir de um contexto muito particular, mas que pode contribuir para se pensar aspectos que são comuns às aulas on-line de língua inglesa em tempos de ensino remoto emergencial e fomentar o debate em torno do ensino-aprendizagem de línguas em contexto mediado pelo uso de tecnologias digitais.

Portanto, para fins de organização textual, além desta introdução e das considerações finais, o artigo traz mais quatro seções. Na primeira, é definido o que é interação discursiva em uma perspectiva dialógica; na segunda, são traçados alguns parâmetros de análise das interações discursivas a partir do contexto espaço-temporal de realização da aula; na terceira, são elencados os aspectos metodológicos da pesquisa; e finalmente na quarta, são analisadas as características das interações discursivas vinculadas às etapas de organização da aula, comparando, sempre que possível, com a aula presencial.

\section{As interações discursivas nas aulas de línguas em uma perspectiva dialógica}

Apresentarei, nesta seção, os princípios que norteiam meu entendimento sobre as interações discursivas nas aulas de línguas em uma perspectiva dialógica. Para isso, é importante assumir, logo de início, que é por meio de enunciados, pertencentes a um determinado gênero do discurso, que nos diri- 
gimos uns aos outros, uma vez que os enunciados são, para Bakhtin (2016), a unidade da comunicação discursiva; dessa forma, a simples réplica de um diálogo cotidiano já pode ser entendida como um enunciado concreto. É, também, por meio de enunciados que o professor se dirige aos alunos e vice-versa. Diante desse quadro, sabemos que a interação verbal, traduzida mais recentemente, no Brasil, por interação discursiva, é um dos pontos centrais de discussão no conjunto da obra de Bakhtin e o Círculo. Volóchinov, por exemplo, no livro Marxismo e Filosofia da Linguagem dedica um capítulo ao tema, denominado $A$ interação discursiva. Neste capítulo, encontramos a famosa metáfora da palavra como uma ponte:

Em sua essência, a palavra é um ato bilateral. Ela é determinada tanto por aquele de quem procede quanto para aquele para quem se dirigi. Enquanto palavra, ela é justamente $o$ produto das inter-relações do falante com o ouvinte. Toda palavra serve de expressão ao "um" em relação ao "outro". [...] A palavra é uma ponte que liga o eu ao outro. Ela apoia uma das extremidades em mim e a outra no interlocutor. A palavra é território comum entre o falante e o interlocutor. (VOLÓCHINOV, 2018, p. 205, grifos no original).

Essa ideia foi posteriormente desenvolvida por Bakhtin em alguns de seus escritos, como, por exemplo, em Questões de literatura e de estética: a teoria do romance e no conhecido texto Os gêneros do discurso. Bakhtin (2016, p. 29) afirma, de forma bastante semelhante à de Volóchinov, que "o falante termina o seu enunciado para passar a palavra ao outro ou dar lugar à sua compreensão ativamente responsiva”. Dessa forma, sabendo que a dinâmica da interação discursiva acontece em torno da relação $e u$ -o-outro, assumo que a interação em sala de aula também não escapa a esse processo. A partir dessa compreensão e ao propor um olhar dialógico sobre as interações em sala de aula, Oliveira, Torga e Ribeiro (2016) refletem sobre as dinâmicas envolvidas nessa interação. Em um primeiro plano, para os autores, o professor aparece como o eu que inicia a interação em função do aluno que está no papel do outro; em outro plano, o aluno é o eu em interação com seu colega de classe ou com o professor, o outro. No dizer dos autores "o professor que assume o papel do eu já assumiu o papel do tu em tantas outras interações e, em sala de aula, quando se calar, ouvirá o aluno, que deixará de ser o tu e passará a ser o eu" (OLIVEIRA; TORGA; RIBEIRO, 2016, p. 82).

Nessa dinâmica, Goulart (2009, p.15), na tentativa de encontrar balizadores para a análise de interações discursivas em sala de aula com base em Bakhtin, caracteriza a aula "como um espaço em que o objetivo dos professores é fazer com que os alunos se apropriem discursivamente de determinados modos de conhecer temas vinculados às diferentes áreas de conhecimento". Assim, como o enunciado reflete/refrata as condições específicas de cada campo da atividade humana, as práticas que são repetidas no dia a dia da escola vão moldando formas de interação discursiva culturalmente transmitidas, efetivando a prática social que convencionalmente denominamos de aula. Isso quer dizer que, recuperando a ideia de Volóchinov (2018, p. 222), “cada situação cotidiana recorrente possui uma determinada organização do auditório e portanto um determinado repertório de pequenos gêneros cotidianos". Dessa forma, cabe ressaltar que a aula tem

'um certo repertório de fórmulas correntes', que organiza o discurso ali produzido de determinadas maneiras: leituras de diferentes tipos e para variados fins (comentada, silenciosa...), conversas, produções escritas, elaboração de resumos, exposição oral, realiza- 
ção de exercícios, esquemas e provas, entre outros (GOULART, 2009, p. 18).

Nessa passagem, mesmo se referindo a uma aula presencial, Goulart enumera diferentes formas de interação discursiva, sejam orais ou escritas. Cada uma delas pode ser caracterizada por estratégias discursivas também mais ou menos estáveis. Por exemplo, é comum que o professor de língua inglesa, após uma pergunta realizada a um aluno que não respondeu corretamente, refaça a pergunta a outro aluno, esperando a resposta correta. Da mesma forma, é comum que o professor repita exatamente o que o aluno disse para tentar corrigir a pronúncia de um determinado vocábulo, ou até mesmo, reformular seu dizer para facilitar a compreensão dos alunos. Diante dessas possibilidades, os pesquisadores da interação didática costumam recorrer ao esquema elaborado por Sinclair e Coulthard (1975) para ilustrar a estratégia discursiva mais usada em uma aula de línguas, qual seja Initiation - Response - Follow-up (IRF). 0 termo em inglês Initiation refere-se à estratégia de abertura da interação iniciada pelo professor, constituída por atos de solicitação, informação, diretivos ou de seleção de falantes. Em seguida, espera-se uma resposta (response) efetuada pelo aluno, constituída por réplicas ou reação ao que foi iniciado pelo professor. E, finalmente, o prosseguimento, ou, em inglês, follow-up, efetuado pelo professor, constituído por atos de aceitação, validação ou comentários.

Ao trazer essa discussão à baila, não quero afirmar que o modelo de Sinclair e Coulthard encerra em si mesmo toda a dinâmica da interação discursiva em sala de aula, como já assinalei ao discutir as diferentes posições entre o eu e o outro na interação; e nem para utilizá-lo como uma categoria pré-estabelecida e procurar sua forma de realização na aula que trarei para a análise. De alguma forma, porém, essa definição serve para pensarmos a sala de aula como um espaço do diálogo. 0 professor, na maioria das vezes, organiza as interações, gerencia as réplicas do diálogo, faz questionamentos e aponta a vez dos alunos falarem. Por isso, as interações discursivas nas aulas de línguas, de forma particular, têm sido descritas com foco na interação do professor com os alunos, procurando as especificidades da interação discursiva na aula, destacando os recursos que são recorrentes, como, por exemplo, na perspectiva de Cicurel (2011), o diálogo interrogativo e os recursos de reformulação constante do dizer.

A interação discursiva em sala de aula, portanto, pode ser caracterizada por diferentes estratégias que dão forma às interações, seja para ensinar ou para aprender. Em uma perspectiva dialógica, podemos dizer que a relativa estabilidade dos acontecimentos em uma aula é vinculada ao tipo de instituição, à estrutura, aos objetivos e à composição social da escola, organizada de um certo modo discursivo, caracterizando, junto com outros elementos, uma cultura escolar (GOULART, 2009). Dessa forma, para dialogar com o trabalho de Goulart, trago, no Quadro 1, inspirado no trabalho de Matêncio (1999) ${ }^{3}$, uma possível organização de uma aula presencial (na coluna da direita) e a caracterização das interações discursivas frequentemente usadas para levar a cabo o objetivo da aula (coluna da esquerda). Isso é feito com o propósito de compararmos, sempre que possível, na análise, as etapas e os tipos de interações discursivas da aula presencial com a aula on -line de língua inglesa.

3 Matêncio (1999) utiliza outro quadro teóricometodológico para construir seu entendimento sobre as interações didáticas. Considero, contudo, o diálogo produtivo com a discussão que estamos desenvolvendo. 
Quadro 1 - Etapas de organização de uma aula presencial

ETAPAS DA AULA

\begin{tabular}{|c|l|}
\hline \multicolumn{1}{|c|}{ ABERTURA } & $\begin{array}{l}\text { Abertura da interação com função preliminar. Realização da cha- } \\
\text { mada, por exemplo. Foco na interação oral entre professor e aluno. }\end{array}$ \\
\hline INTRODUÇÃo & $\begin{array}{l}\text { Abertura efetiva da interação quando a seu objetivo didático. Início } \\
\text { efetivo das atividades do dia. Foco tanto na interação oral quanto } \\
\text { na interação escrita. }\end{array}$ \\
\hline DESENVOLVIMENTO & $\begin{array}{l}\text { Desenvolvimento das tarefas que constituem as atividades do dia. } \\
\text { Foco, muitas vezes, na interação escrita quando o aluno responde } \\
\text { ao exercício, por exemplo. }\end{array}$ \\
\hline CONCLUSÃo & $\begin{array}{l}\text { Encerramento das atividades. Pode coincidir com a etapa de en- } \\
\text { cerramento. Foco na interação oral entre professor e aluno, com } \\
\text { perguntas e respostas. }\end{array}$ \\
\hline ENCERRAMENTO & $\begin{array}{l}\text { Encerramento da interação com função de conclusão e despedida. } \\
\text { Não ocorre sempre. }\end{array}$ \\
\hline
\end{tabular}

Fonte: elaborado e ampliado a partir de Matêncio (1999).

Para compreender as características das interações discursivas em uma aula on -line de língua inglesa na plataforma Google Meet, por seu turno, precisamos, além dos elementos apresentados acima, levar em consideração que estamos vivendo um tempo de pandemia e isolamento social e que o uso de plataformas digitais, como o Google Meet, tornou-se um dos espaços de acontecimento da aula síncrona. Essas especificidades espaço-temporais demandam um olhar cuidadoso sobre as interações discursivas, a fim de compreender melhor as potencialidades e os desafios que conduzem, de uma forma ou de outra, à adaptação e/ou à mudança de práticas docentes e discentes e das próprias interações. Para dar conta disso, discuto, a seguir, alguns aspectos espaço-temporais nos quais emergem a aula on-line de língua inglesa, traçando alguns parâmetros para a análise.

\section{INTERAÇÃO DISCURSIVA}


to de crise política em nosso país, com um governo que propaga fake news, desinformação e anticientificismo, relativizando a gravidade da doença, colocando cada vez mais em risco a saúde do cidadão (para uma revisão sobre o assunto, ver RECUERO; SOARES, 2020). Exemplo disso, além dos muitos já registrados e divulgados amplamente pela imprensa, é a desorganização e o desinteresse do governo federal em promover um plano nacional de imunização. Paralelo a isso, o trabalho dos professores nunca parou. Mesmo sendo acusados pelo mesmo governo de não quererem trabalhar ${ }^{4}$, no estado do Ceará, por exemplo, as atividades de forma remota foram retomadas logo no mês de março de 2020. Tudo isso, certamente, atravessa e se relaciona organicamente com as interações discursivas que acontecem durante um encontro on-line com os alunos; afinal, como afirma Bakhtin (2016, p. 16-17), "a língua passa a integrar a vida através de enunciados concretos (que a realizam); é igualmente através de enunciados concretos que a vida entra na língua".

Dito isso, passo, então, ao ponto (ii) o espaço em que a aula on-line acontece. Como já informado, foi durante o ensino remoto emergencial que a SEDUC-CE oficializou a plataforma Google Meet como o espaço de realização das aulas on-line. Conhecer o funcionamento da plataforma pode auxiliar na caracterização das interações discursivas, uma vez que elas acontecem em seus limites espaço-temporais. $\mathrm{Na}$ Figura 1, retirada de uma notícia do site da Rádio Araguaia AM, portanto, de domínio público, é apresentada a foto de um encontro realizado na plataforma.

Figura 1 - Reunião na plataforma Google Meet

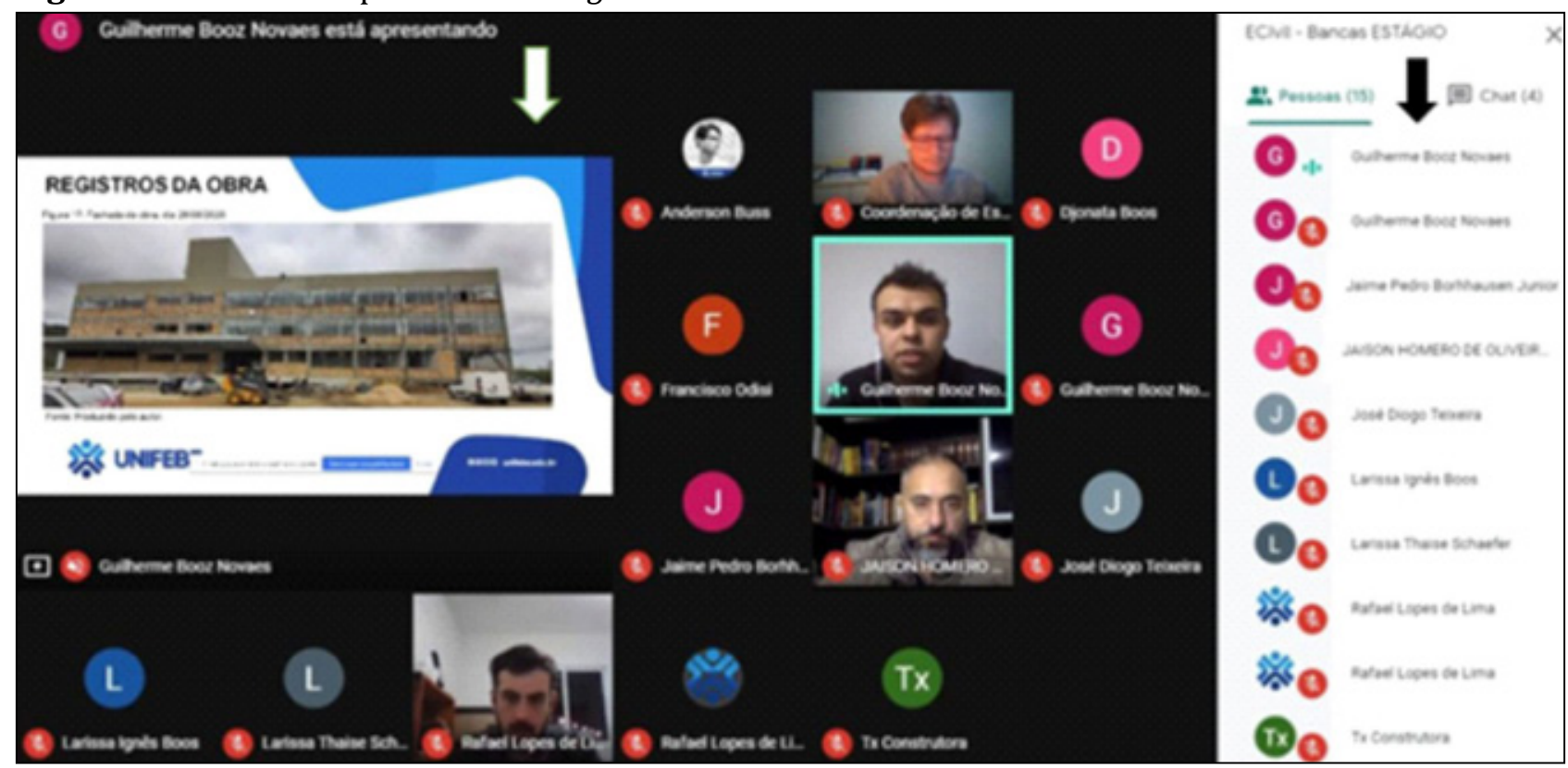

Fonte: https://araguaiabrusque.com.br/noticia/academicos-apresentam-trabalhos-de-conclusao-de-curso-viagoogle-meet/66751. Acesso em 21 out. 2020.

Como vemos na imagem, ao utilizar a plataforma Google Meet, é possível o en-

4 A live em que o Presidente Jair Bolsonaro acusa os professores de não querem trabalhar pode ser acessada no link: https://youtu.be/JsIdVBSushc. Acesso em: 08 maio 2021. contro on-line de diversas pessoas, sendo permitidos até 100 participantes na versão gratuita. Seu uso tem impactado decisivamente as formas de interação social. Como exemplo, podemos destacar os deslocamentos espaço-temporais, do presencial para o remoto, de diversas atividades, se- 
jam de estudo ou de trabalho, dos mais variados campos da atividade humana. Com isso, seja de suas próprias casas, ou até mesmo do trânsito ou de um consultório médico, os participantes do encontro podem interagir de forma oral, ligando seus microfones, ou de forma escrita, usando o chat. Na aba Pessoas (seta preta), aparecem três pontos verdes assimétricos, como se fossem uma pequena onda sonora, no ícone de quem está com a palavra; e um ícone vermelho com o desenho de um microfone cortado por um traço em paralelo para quem está com o microfone desligado. Devido a esse layout, fica fácil identificar quem está falando e resolver problemas de interferência sonora. 0 administrador do encontro pode, a qualquer momento, desativar o áudio de outro participante. Isso geralmente é feito quando um microfone está ligado, produzindo algum tipo de barulho.

A foto do perfil, muitas vezes, não se trata de uma foto do participante, pode ser uma paisagem ou algo semelhante; em outros casos, vemos o que pode ser a letra inicial do nome do participante. Também do lado direito da tela (seta preta) encontramos outros dois ícones. 0 primeiro mostra a lista de pessoas que participam do encontro e o segundo mostra as mensagens que estão sendo escritas no chat. Durante o encontro, é possível que os participantes entrem e saiam, desde que a opção esteja habilitada pelo administrador. A entrada/saída é registrada por uma caixa de diálogo que surge no canto inferior da tela. Quando há oscilação na conexão com a internet, entradas e saídas são frequentes. É possível, também, que seja compartilhada a tela de qualquer um dos participantes (seta branca). Neste momento, quem está compartilhando a tela fica impedido de ver as mensagens digitadas no chat, bem como de ver os demais par- ticipantes do encontro. Esse fato, tem sido apontado frequentemente, tanto nas aulas que ministro como nas aulas das quais participo, como um dos fatores mais negativos da interação na plataforma.

São nesses limites espaço-temporais, discutidos no ponto (i) e (ii), que o professor e os alunos produzem seus diálogos, esperando sempre uma atitude ativo-responsiva do interlocutor em função da construção de um projeto comunicativo, promovendo diferentes formas de interações discursivas. Entendo que os diálogos em sala de aula e cada uma de suas réplicas "por mais breve e fragmentária que seja, tem uma conclusibilidade específica ao exprimir certa posição do falante que suscita resposta, em relação à qual se pode assumir uma posição responsiva (BAKHTIN, 2016, p. 30). Essas réplicas do diálogo, ou seja, as posições responsivas do falante, podem assumir diferentes formas, pressupondo a relação entre professor-aluno, aluno-professor, aluno-aluno, seja de pergunta-reposta, afirmação-concordância, comando-execução, participação-incentivo. Assim, pensando especificamente na análise das interações discursivas em sala de aula, encontramos em Questão de Literatura e Estética: a teoria do romance, uma pista metodológica para a caracterização das interações discursivas na aula on-line de língua inglesa na plataforma Google Meet durante o ensino remoto emergencial. Vejamos o que Bakhtin (2002, p. 141) afirma:

Pois para a apreciação cotidiana, e para adivinhar o significado verdadeiro das palavras de outrem pode ser decisivo saber-se quem fala e em que precisas circunstâncias. A compreensão e o julgamento cotidiano não separam a palavra da pessoa totalmente concreta do falante (o que é possível na esfera ideológica). Além disto, é muito importante situar a conversação; quem esteve presente no ato, que expressão tinha, como era sua mímica 
ao falar, quais as nuanças de sua entonação enquanto falava.

A partir desse excerto, advogo que para a análise das interações discursivas em sala de aula serem bem caracterizadas, é necessário, em uma perspectiva dialógica, saber quem fala e em que precisas circunstâncias. Foi a partir desse parâmetro de análise que busquei definir os elementos contextuais, ou seja, as precisas circunstâncias que envolvem essa interação, descrevendo o tempo e o espaço em que ela surge. Além disso, irei situar, na seção de análise, as interações discursivas em sala de aula levando em consideração quem fala e como fala. Por isso, quando preciso, serão descritas as expressões corporais do professor e as nuanças de sua entonação ao falar. Acredito que tudo isso é engendrado pelo enunciado concreto em função da construção de um projeto comunicativo em que os alunos podem relacionar a palavra na língua estrangeira ao gesto/expressão do professor e produzir a partir daí uma compreensão. Nesse sentido, vale destacar que, em uma perspectiva dialógica, a compreensão está sempre relacionada à resposta. Sobre isso, Bakhtin (2002, p. 90, grifos meus) afirma

Na vida real do discurso falado, toda compreensão concreta é ativa: ela liga o que deve ser compreendido ao seu próprio círculo, expressivo e objetal e está indissoluvelmente fundido a uma resposta, a uma objeção motivada - a uma aquiescência. Em certo sentido, o primado pertence justamente à respos$t a$, como princípio ativo: ela cria o terreno favorável à compreensão de maneira dinâmica e interessada. A compreensão amadurece apenas na resposta. A compreensão e a resposta estão fundidas dialeticamente e reciprocamente condicionadas, sendo impossível uma sem a outra.

Como alerta Bakhtin, a compreensão e a resposta estão fundidas dialeticamente, uma depende da outra. Nessa perspectiva, todo enunciado, inclusive as réplicas do diálogo em sala de aula, deve ser caracterizado como uma resposta a enunciados anteriores, que procede de alguém e é endereçado a alguém, como elo na complexa relação entre o já-dito, o dito e o ainda-não dito, uma vez que "toda compreensão da fala viva, do enunciado vivo é de natureza ativamente responsiva" (BAKHTIN, 2016, p. 25). Trazendo para o contexto da aula on-line, a compreensão dos interlocutores será concretizada a partir da resposta que foi suscitada. $\mathrm{Na}$ interação discursiva em sala de aula, por exemplo, o aluno precisa tomar uma posição ativo-responsiva frente ao enunciado do professor, que pode ser compreendido, no momento da interação, como uma pergunta, um pedido, uma correção, um elogio etc. Ao passo que se torna respondente, o aluno assume o lugar de interlocutor esperando, consequentemente, uma resposta do professor e/ou de seus colegas, em uma cadeia dialógica infinita em que não existe a primeira e nem a última palavra. Ao adotar esse olhar sobre as interações discursivas em sala de aula, trago, na próxima seção, os aspectos metodológicos da pesquisa.

\section{Aspectos metodológicos}

Sigo, neste trabalho, as orientações de uma pesquisa dialógica proposta por Bakhtin (2017, p. 44), que busca "superar a perniciosa separação e a mútua impenetrabilidade entre cultura e vida". Dessa forma, para compreender as características das interações discursivas em uma aula on-line de língua inglesa na plataforma Google Meet são apresentadas interações discursivas provenientes da gravação de uma de minhas aulas que aconteceu no dia 17 de setembro de 2020. A turma era do segundo 
semestre do curso de inglês do CCI Jóquei. Os alunos da turma eram adolescentes entre 15 e 17 anos de idade, cursando, em sua maioria, o primeiro ano do ensino médio da rede pública estadual do Ceará. A aula, nesse contexto, foi planejada para alunos iniciantes que estavam na fase de aquisição das noções básicas do idioma. 0 conteúdo do dia era referente à Unidade 8 , Lição $\mathrm{B}$, com o tema Things to buy. 0 objetivo da aula era falar sobre acessórios e perguntar sobre preços em inglês. Neste dia, estavam presentes 13 alunos, do total de 17 alunos matriculados.

Para iniciar a gravação da aula, os alunos foram informados que os dados seriam usados para a pesquisa e que o anonimato de cada um seria preservado. Cientes dessas condições, os alunos escreveram no chat "sim", concordando com a gravação. Todos os alunos concordaram e, para efeitos de transcrição, denominarei minha participação na interação como Professor e a dos alunos com nomes fictícios aleatoriamente escolhidos. Quanto às convenções de transcrição, temos a demarcação de: a) pausa (...); b) comentários descritivos do transcritor ( ( )); e c) alongamento de vogais (::).

Ilustro a análise com exemplos de interações retirados da gravação da aula que fica disponível no e-mail utilizado para acessar à plataforma. Para tanto, assisti a aula algumas vezes e retirei exemplos de interações que julgo representativos para caracterizar as interações discursivas em uma aula on-line de língua inglesa na plataforma Google Meet, seguindo, analiticamente, os parâmetros apresentados na seção anterior, a saber, a caracterização das interações discursivas a partir do contexto de realização da aula e das atitudes ativo-responsivas dos interlocutores - professor e alunos - em função da construção de um projeto comunicativo no qual os alunos pudessem falar sobre acessórios e perguntar sobre preços em inglês, comparando, sempre que possível, com as interações da aula presencial. Trago também um exemplo de interação no WhatsApp antes da entrada dos alunos na plataforma para ilustrar a Etapa 1 da aula. Recorro, em alguns momentos, ao Quadro 1, apresentado na seção 1 , para fazer o paralelo entre a aula presencial e a aula remota. Para concluir, apresento um quadro que resume as características das interações discursivas vinculadas às etapas de organização da aula on-line.

Como faço a descrição de minha própria prática, as interpretações trazidas, por certo, atravessam axiologicamente meu ser professor e meu ser pesquisador. Esse deslocamento que realizo, da condição de professor para a condição de pesquisador, permite-me, no entanto, olhar exotopicamente para a minha prática e transformá-la em objeto de pesquisa, que, dialogicamente, está ligado e informa a minha atividade de ensino. É a partir dessas condições que procedo com as análises.

\section{Interações discursivas em uma aula on-line de língua inglesa na plataforma Google Meet}

No horário agendado para o início da aula, os alunos acessam a plataforma via link disponibilizado na descrição do grupo da turma no WhatsApp e no mural da plataforma Google sala de aula. Mesmo assim, alguns deles enfrentam problemas de acesso. Podemos, dessa forma, assumir que, na aula on-line, a Etapa 1 é o acesso à plataforma. Essa Etapa demanda interações escritas no grupo da turma no WhatsApp para a viabilização da entrada na plataforma. A Figura 2 , traz um exemplo desse tipo de interação. 
Figura 2 - Interação de viabilização da entrada na plataforma

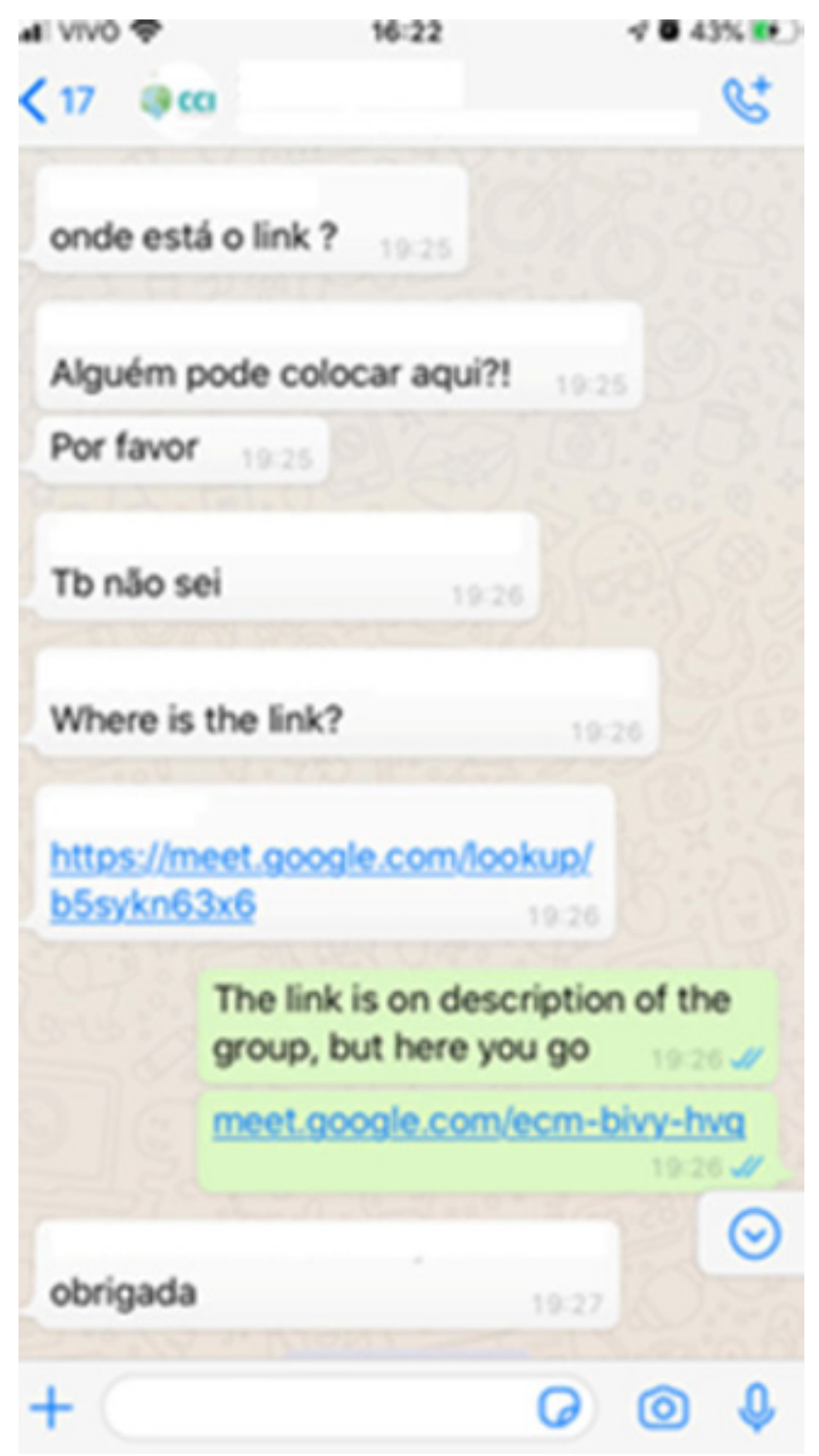

Fonte: arquivo pessoal.

Essa interação é iniciada por perguntas dos alunos, escritas no grupo da turma no WhatsApp, sobre o link para permitir o acesso à plataforma. A pergunta inicial "onde está o link" gera uma atitude responsiva em um aluno que diz "alguém pode colocar aqui”. Diante da interação em português, outro aluno, escrevendo em inglês, pergunta "where is the link?". Imediatamente um dos alunos posta o link da aula e, em seguida, o Professor também posta o link e relembra que ele está na descrição do grupo. Diferente da aula presencial, descrita por Matêncio
(1999), na aula on-line de língua inglesa na plataforma Google Meet, a interação discursiva acontece antes do início das interações sobre o conteúdo e até mesmo antes da entrada dos alunos na plataforma e é, como vimos, protagonizada pelos alunos que assumem o papel do eu na interação, endereçando seus enunciados aos demais colegas e ao professor, o outro. Essa dinâmica é representativa dos diferentes posicionamentos entre o eu e o outro salientados por Oliveira, Torga e Ribeiro (2016), na qual tanto os alunos como o professor ocupam o papel do eu e do outro na interação, desafiando a ideia de que o professor seria sempre o responsável pelo início da interação em sala de aula de acordo com o esquema de Sinclair e Coulthard (1975).

Na Etapa 2 da aula, enquanto os alunos entram no Google Meet, o Professor inicia a interação dando as boas-vindas. Esse tipo de interação discursiva pode ser caracterizada a partir de cumprimentos como "good morning" e de perguntas como "hello, how are you?" por parte do professor e não está vinculada, pelo menos diretamente, ao conteúdo a ser trabalhado no dia. As respostas vêm, por vezes, de forma oral, quando o aluno liga o microfone, ou de forma escrita, quando o aluno digita no chat a resposta. Frequentemente os alunos se cumprimentam, especialmente escrevendo no chat. Esta Etapa é muito semelhante à Etapa 1 da aula presencial descrita por Matêncio (1999), e, por isso, também será denominada de abertura.

Depois de cinco minutos em média, quando a maioria dos alunos está na sala de aula on-line, é iniciada a Etapa 3 da aula. Nesta Etapa, compartilho com a turma a minha tela com o slide que traz o objetivo da aula e a explicação do conteúdo. Nesse momento, deixo de ver a turma e vejo apenas a minha tela. Contudo, tenho praticado colocar a ja- 
nela que compartilho lado a lado com a janela do Google Meet, como mostra a Figura 3. Isso permite ver, ao mesmo tempo, as interações no chat e o material compartilhado. Às vezes, os alunos reclamam que a janela compartilhada é pequena, dificultando a vi- sualização. A maioria dos alunos usa o celular para participarem da aula, o que torna a visualização também mais problemática. Por isso, pontualmente, coloco a janela em modo de tela inteira e, logo após, retomo a apresentação com as janelas lado a lado.

Figura 3 - Modo de compartilhamento de tela na aula on-line de língua inglesa

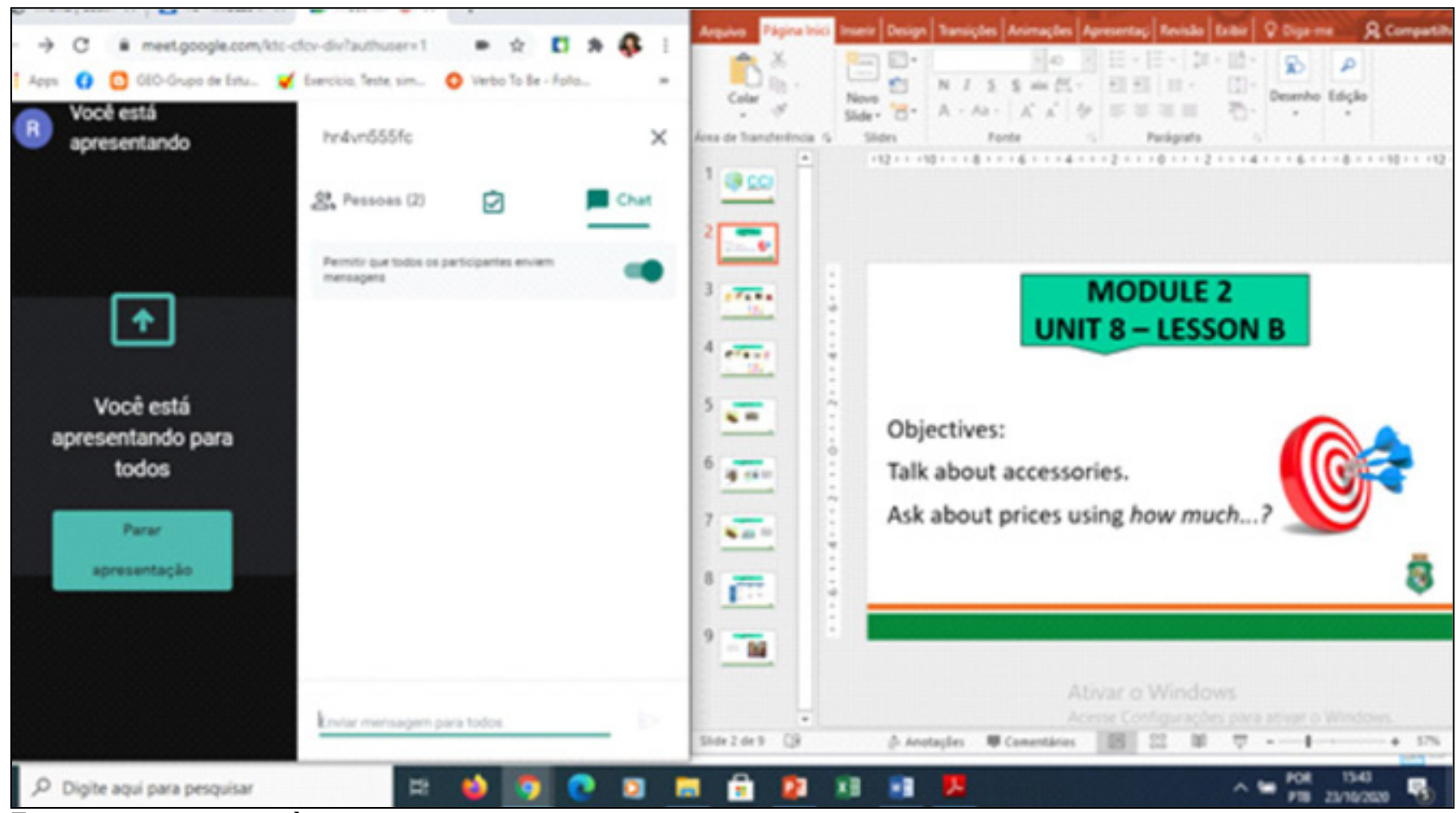

Fonte: arquivo pessoal.

A Etapa 3, neste contexto, será nomeada de explicação do conteúdo. Ela guarda muito em comum com a Etapa de desenvolvimento da aula presencial (MATÊNCIO, 1999). Isto é, durante essa Etapa são desenvolvidas as tarefas do dia, explicação do conteúdo, resolução de exercícios etc. No contexto da aula on-line de língua inglesa em análise, no entanto, a Etapa de desenvolvimento se desdobra em duas, ela se inicia com a explicação do conteúdo e segue com a produção oral dos alunos, como veremos adiante. Abaixo, ilustro um tipo de interação discursiva desta Etapa da aula que denomino interação de certificação:

Professor: Can you see the PowerPoint? ((segue uma pequena pausa)).
Joana: Yes.

Professor: All right.

A depender da qualidade da internet do professor e dos alunos, as respostas, sejam orais ou escritas no chat, podem demorar para acontecer. Sempre é necessário que o professor se certifique de que os alunos estão vendo a tela compartilhada e que podem acompanhar sem grandes dificuldades. Por vezes, pode acontecer de a tela compartilhada congelar. Por isso, perguntas como "can you see?" e "can you hear me?" são características desta interação discursiva que emerge vinculada a esse novo contexto de aula. Afinal, como insiste Bakhtin (2016), o objetivo da interação é conectar os interlocutores por meio do diá- 
logo e só pode haver diálogo (em sala de aula) quando há uma resposta. As respostas dos alunos vêm, muitas vezes, de forma oral, pois, devido ao repertório dos pequenos gêneros (VOLÓCHINOV, 2018), ou seja, das fórmulas recorrentes de interação, os alunos já sabem que o professor não consegue ver o chat ao mesmo tempo que compartilha a sua tela.

Da mesma forma, ainda durante essa Etapa, busco incentivar a participação dos alunos no chat e verificar se todos estão atentos à explicação. Não é incomum que os alunos, como estão em suas casas ou em outros espaços, como no trabalho, no veterinário ou, até mesmo, em um hospital, fiquem desatentos à aula. Tal composição social dos alunos é própria de uma aula on -line durante o ensino remoto emergencial e define bem o adjetivo emergencial, permitindo que os campos das atividades íntimas se vinculem aos das atividades educacionais. Levando em consideração o pressuposto de que para se entender uma interação discursiva, de acordo com Bakhtin (2002), precisamos compreender as precisas circunstâncias em que o discurso aparece, posso afirmar que a aula, deslocada de um espaço físico para uma plataforma digital, ressignifica o que é institucional, promovendo, ao mesmo tempo, interações espaço-temporais diversas. Diante de tal composição, na maioria das vezes, os alunos avisam sobre a impossibilidade de falar durante a aula, seja porque estão fazendo o almoço ou esperando para serem atendidos em um consultório. Por isso, faço perguntas sobre o conteúdo e peço para eles escreverem as respostas no chat, quando possível. Esse tipo de interação discursiva irei denominar de interação de incentivo. Podemos observar um exemplo que caracteriza esse tipo de interação a seguir:
Professor: Last class, we talked (...) about the clothes, ri(::)ght? So how to say pants, jacket, jeans. What else? Do you remember the names of the clothes? Can you write on the chat? The na(::)mes (...) blouse, t-shirt, please (...) if you remember, please just (...) write on the cha(::)t, please ((fazendo movimentos de digitar com as mãos suspensas)). The name of the clothes ((dito muito pausadamente)). Let me see if you remember.

((pausa para conferência do chat)).

Professor: ((professor ler o chat)) skirt, jacket, shoes, skirt, drees, short, (...) right, shoes, skirt. What el(::)se?, pants. Right. Socks and shoes. Right. (...) Gabriele, very good (...) tie, right, pants (...). How can I say boné ((apontando para a cabeça)) in English? Do you remember? (...) Boné is an accessory. Cap! Ri(::)ght. Very good!

A interface entre a produção oral e a produção escrita, ao meu ver, é uma das principais características desse tipo de interação e uma novidade da aula on-line. Nela, percebemos que o professor inicia o diálogo oralmente e a resposta dos alunos acontece de forma escrita, no chat. 0 professor organiza a interação, usando expressões interrogativas como "What else?" e "Do you remember?", incentivando a participação dos alunos. Os alunos escutam o professor, mas também veem os seus gestos transmitidos pela câmera. Dessa forma, o professor complementa o comando "write on the chat" com o gesto de digitar com as mãos suspensas. Essa característica contribui para que os alunos compreendam e, portanto, respondam às perguntas do professor, afinal, os gestos, também são parte da composição do enunciado e a compreensão sempre está fundida com a resposta (BAKHTIN, 2002). Quando os alunos digitam as respostas, o 
professor lê o nome "cap" e parabeniza, incentivando os alunos, com expressões do tipo "very good!".

Depois da Etapa 3 da aula, dedicada à $e x-$ plicação do conteúdo e a interação por meio do chat, inicia-se a Etapa 4, a produção oral dos alunos. Ela pode acontecer por meio de perguntas e respostas ou leitura de pequenos diálogos, simulando o uso da língua alvo. No caso em tela, a opção foi pela leitura de um diálogo sobre uma compra em loja, já que um dos objetivos da aula era perguntar sobre preços em inglês usando expressões como "how much". Os alunos deveriam ler a conversação em duplas, cada um dos alunos assumindo um papel, o de vendedor(a) ou o de cliente. Antes de os alunos começarem os diálogos, expliquei o contexto da conversação; foram feitas perguntas sobre o local e as personagens envolvidas na cena. Após sanar dúvidas de vocabulário, a interação, que caracteriza a Etapa 4, denominada interação de comando, prosseguiu da seguinte forma:

Professor: So class, let's practice the conversation, ri(::)ght? In pa::irs. So please, Alan and Darlene. Alan, you are going to be letter $A(. .$.$) and Darlene is going to be letter$ $\mathrm{B}$, right?
Alan: Right!
((pequena pausa))
Professor: You can start, Alan.

Nesse diálogo, o professor inicia a interação orientando como será feita a atividade, nomeando os alunos para a realização da tarefa. Nota-se que o aluno Alan usa a expressão "right" como atitude ativo-responsiva ao comando do professor. Porém, após pequena pausa, foi necessário que o professor reformulasse seu comando, dizendo "you can start, Alan". Esse exemplo ilustra que é comum, na aula on-line, a demora entre as réplicas do diálogo e a dúvida de que o aluno tenha ouvido a fala do professor devido aos frequentes problemas de conexão, por isso se faz necessário, talvez de forma mais recorrente do que já acontecia na aula presencial (CICUREL, 2011), a reformulação do que está sendo dito para promover a continuidade da interação. Em outros momentos, o professor alongou vogais para dar ênfase a alguns de seus comandos. A palavra "pairs", por exemplo, foi alongada, possivelmente para produzir a compreensão de que os alunos trabalhariam em duplas. Dessa forma, tanto os gestos, como a entonação (BAKHTIN, 2002), que compõe o todo do enunciado, são ativados no projeto de dizer do professor para suscitar a atitude ativo-responsiva dos alunos, no caso, a leitura do diálogo em duplas em função da construção de um projeto comunicativo no qual os alunos pudessem falar sobre acessórios e perguntar sobre preços em inglês.

Vale salientar que na aula on-line de língua inglesa continuamos privilegiando o trabalho com o role play, isto é, leitura e emulação de diálogos. Investir nesse tipo de interação pode ser uma resposta mais imediata ao ensino remoto emergencial, ou seja, foi o mais fácil ou viável de ser feito na aula on-line naquele momento. Essa prática também pode ser entendida como uma resposta ao contexto institucional, ao cumprimento do conteúdo programático e a sequência apresentada no livro didático, como já antecipou Goulart (2009). A cultura institucional, de acordo com a autora, acaba influenciando nas discursividades que são possíveis durante a aula. Por isso que as interações discursivas precisam ser entendidas, em uma perspectiva dialógica, como uma resposta, não apenas aos interlocutores imediatos - professor e alunos -, mas também, ao contexto sócio-histórico 
no qual emergem, ao campo de atividade no qual estão inseridas.

No último exemplo, ainda durante a Etapa 4 da aula, trago uma interação discursiva que ilustra uma interação oral interrompida. Essa interação se caracteriza pela impossibilidade de participação oral, pois a aluna que foi solicitada para interagir estava com problemas no microfone e, por isso, não pôde dar continuidade à leitura do diálogo. Apesar desse tipo de interação ser possível em uma aula presencial, no caso de um aluno estar doente e impossibilitado de falar, por exemplo, as especificidades, aqui, são outras.

Professor: Now, Glória and Júlia. Glória, you are going to be letter A. Júlia is going to be letter B, right? So please, Glória you can start.

Glória: Can I help you?

((pausa e um barulho de mensagem chegando no chat)).

Glória: Ah (:), não tá prestando não, o microfone.

Professor: Ok, So, então ((pausa)). So, Glória and Joana, right? (...). Glória and Joana. Glória, ple(::)ase, start again.

Glória: Ok.

A característica dessa interação é a reformulação discursiva do comando que foi programado anteriormente pelo professor (CICUREL, 2011). Assim, quando a aluna Glória começa a ler a conversação, percebemos uma pausa. Seguida da pausa, vem a resposta no chat da aluna Júlia que informa ao professor que seu microfone não estava funcionando. Mesmo impedida de falar, a aluna compreende e responde ao professor escrevendo no chat. Como o professor não estava vendo a tela, quem replica o diálogo é a aluna Glória que assume o papel do eu na interação, ligando o microfone e falando, em português, que o microfone da colega não estava funcionando. Depois da situação inesperada, quando retoma a fala, o professor usa a expressão "so" e o equivalente em português "então", gerando uma acentuada pausa, possivelmente uma resposta aos enunciados que dizem que o professor de inglês precisa falar apenas em inglês durante a aula. Para resolver a situação, o Professor, depois da pausa, reformula seu comando inicial, nomeando outra aluna como dupla de Glória e a interação continua até a última dupla ler o diálogo. Expressões do tipo "excellent" e "very good" seguidas dos nomes dos alunos são ditas ao final de cada leitura, evidenciando que as interações de incentivo não são características apenas da Etapa 3 da aula.

Finalmente, na Etapa 5, denominada de encerramento, o Professor (i) retoma o objetivo da aula; (ii) avisa sobre o conteúdo do próximo encontro e pede para os alunos realizarem as atividades disponíveis no Google sala de aula; (iii) despede-se. Essa etapa é muito semelhante e mescla, as etapas de conclusão e encerramento da aula presencial conforme apresentado no Quadro 1 adaptado de Matêncio (1999). A interação discursiva de despedida é caracterizada com expressões como "thank you for coming" e "see you next class". Alguns alunos respondem oralmente ao professor e outros usam o chat.

Para concluir esta seção, resta dizer que, por meio das orientações metodológicas de Bakhtin (2002), busquei caracterizar as réplicas do diálogo da aula como uma atitude ativo-responsiva dos interlocutores - professor e alunos - em função da construção de um projeto comunicativo no qual os alunos pudessem falar sobre acessórios e perguntar sobre preços em inglês. A partir da 
análise empreendida, no Quadro 2, são resumidos os tipos de interações discursivas vinculados às etapas de organização da aula on-line de língua inglesa na plataforma Google Meet, apontando as características de cada um.

Quadro 2 - Interações discursivas em uma aula on-line de língua inglesa na plataforma Google Meet

\begin{tabular}{|c|c|c|}
\hline ETAPA DA AULA & $\begin{array}{l}\text { TIPO DE INTERAÇÃO DIS- } \\
\text { CURSIVA }\end{array}$ & CARACTERÍSTICAS \\
\hline Acesso à plataforma & $\begin{array}{l}\text { Viabilização da entrada na } \\
\text { plataforma. }\end{array}$ & $\begin{array}{l}\text { Perguntas escritas pelos alunos no grupo } \\
\text { de WhatsApp sobre o link da aula. Professor } \\
\text { responde postando o link. }\end{array}$ \\
\hline Abertura & Boas-vindas aos alunos. & $\begin{array}{l}\text { Professor usa expressões como "good mor- } \\
\text { ning" e "how are you" para cumprimentar os } \\
\text { alunos. Os alunos respondem oralmente ou } \\
\text { escrevem no chat. }\end{array}$ \\
\hline \multirow{2}{*}{$\begin{array}{l}\text { Explicação do conteú- } \\
\text { do }\end{array}$} & Interação de certificação & $\begin{array}{l}\text { Professor usa expressões como "can you } \\
\text { see" para se certificar de que os alunos es- } \\
\text { tão atentos à aula ou com algum problema } \\
\text { técnico. }\end{array}$ \\
\hline & Interação de incentivo & $\begin{array}{l}\text { Professor usa expressões do tipo "what else" } \\
\text { e "very good" para incentivar a participação } \\
\text { dos alunos. }\end{array}$ \\
\hline \multirow{3}{*}{$\begin{array}{l}\text { Produção oral dos } \\
\text { alunos }\end{array}$} & Interação de comando & $\begin{array}{l}\text { Professor usa expressões no imperativo } \\
\text { como "Let's practice the conversation" com- } \\
\text { plementada com gestos e mudança na ento- } \\
\text { nação. Os alunos demoram na réplica oral. }\end{array}$ \\
\hline & Interação oral interrompida & $\begin{array}{l}\text { Professor reformula oralmente o comando } \\
\text { feito aos alunos. Alunos respondem no chat } \\
\text { para garantir a continuidade da interação. }\end{array}$ \\
\hline & Interação de incentivo & $\begin{array}{l}\text { Professor usa expressões como "excellent" e } \\
\text { "very good" seguidas dos nomes dos alunos } \\
\text { ao final de cada leitura. }\end{array}$ \\
\hline Encerramento & Interação de despedida & $\begin{array}{l}\text { Professor usa expressões do tipo "thank you } \\
\text { for coming" e "see you next class". Os alunos } \\
\text { respondem oralmente e por escrito no chat. }\end{array}$ \\
\hline
\end{tabular}

Fonte: elaboração própria.

A análise ilustra que uma aula on-line de língua inglesa na plataforma Google Meet, du-

rante o ensino remoto emergencial, possui tipos relativamente estáveis de interações, como resumido no Quadro 2. Portanto, reafirmo que as interações discursivas são diversas, mas organizadas a partir de um repertório de fórmulas recorrentes (GOU-
LART, 2009) e, na aula on-line, pelas condições sócio-históricas específicas em que estamos vivendo devido à pandemia da covid-19, elas assumem vicissitudes diferentes da aula presencial, apesar de manterem com ela muitas semelhanças. 


\section{Considerações finais}

Como foi anunciado na introdução deste trabalho, o objetivo era compreender as características das interações discursivas de uma aula on-line de língua inglesa na plataforma Google Meet. A análise permitiu, ao assumirmos um olhar dialógico, que as interações discursivas entre professor e alunos fossem caracterizadas a partir do contexto de realização da aula, levando em consideração as atitudes ativo-responsivas dos interlocutores - professor e alunos - em função da construção de um projeto comunicativo no qual os alunos pudessem falar sobre acessórios e perguntar sobre preços em inglês comparando, sempre que possível, com as interações da aula presencial. 0 estudo apresentou, portanto, um panorama das características das interações discursivas em uma aula on-line de língua inglesa na plataforma Google Meet.

A análise das interações discursivas e de suas características demonstra, de forma geral, que nesta aula on-line de língua inglesa na plataforma Google Meet os principais desafios tem sido os relacionados à conexão com a internet e ao funcionamento dos microfones que impede, por vezes, a participação oral de todos os alunos. Destaco, ainda, a possibilidade de resposta dos alunos no chat pode ser compreendida como um aspecto positivo desse contexto, pois mesmo diante de problemas técnicos, garante a continuidade da interação e a participação de todos os alunos.

Por fim, mesmo de caráter preliminar e sobre um contexto muito situado - uma pequena narrativa -, esta pesquisa pode ser um instrumento para a compreensão mais detalhada das características das interações discursivas em uma aula on-line de língua inglesa. Dessa forma, as pesquisas que as- sumem um olhar dialógico sobre as interações discursivas podem, ainda, contribuir para o campo da LA, no que se refere ao ensino-aprendizagem de línguas e à formação do professor, provocando reflexões para se pensar aspectos que são comuns às aulas on-line de língua inglesa em tempos de pandemia e fomentar o debate em torno do ensino-aprendizagem de línguas em contexto mediados pelas tecnologias educacionais.

\section{Referências}

BAKHTIN, M. M. Os gêneros do discurso. Tradução de Paulo Bezerra.São Paulo: Editora 34, 2016.

BAKHTIN, M. Para uma filosofia do ato responsável. Tradução de Valdemir Miotello e de Carlos Alberto Faraco. São Carlos: Pedro \& João Editores, 2017.

BAKHTIN, M. Questões de literatura e de estética: a teoria do romance. Tradução de Aurora Fornoni Bernardini, José Pereira Júnior, Augusto Góes Júnior, Helena Spryndis Nazário e Homero Freitas de Andrade. São Paulo: Editora Hucitec, 2002.

BASTOS, R. L. G.; LIMA, S. de C. Narrativas de aprendizagem de inglês em tempos de pandemia. In: OLIVEIRA, K. C. C. de; ALBUQUERQUE, F. G. de; ARAÚJO, A. da S.; SANTIAGO, A. G. J. de (org.). Reflexões sobre o ensino de línguas e literatura, formação docente e material didático. São Carlos: Pedro \& João Editores, 2020. p. 75-91.

CICUREL, F. De l'analyse des interactions en classe de langue à l'agir professoral : une recherche entre linguistique interactionnelle, didactique et théories de l'action. Pratiques, [S.L.], n. 149150, p. 41-55, 15 jun. 2011.

GOULART, C. Em busca de balizadores para a análise de interações discursivas em sala de aula com base em Bakhtin. Revista de Educação Pública, [S. l.], v. 18, n. 36, p. 15-31, 2012.

PAES, F. C.; FREITAS, S. Trabalho docente em tempos de isolamento social. Revista Linguagem em Foco, Fortaleza, v. 12, n. 2, p. 129-149, 21 set. 2020. 
OLIVEIRA, A. S. S. de. TORGA, V. L. M.; RIBEIRO, M. D'A. A. A interação verbal em sala de aula: leituras bakhtinianas sobre o lugar da palavra no processo de ensino-aprendizagem. Caderno Seminal Digital. Rio de Janeiro, v. 19, n. 19, 29 jul. 2013.

RECUERO, R.; SOARES, F. O Discurso Desinformativo sobre a Cura do COVID-19 no Twitter: Estudo de caso. E-Compós, [S. 1.], Ahead of print, 10 set. 2020 .

SINCLAIR, J. MC. H., COULTHARD, R.M. Towards an Analysis of Discourse. Oxford University Press, 1975.

VOLÓCHINOV, V. Marxismo e filosofia da linguagem: problemas fundamentais do método sociológico na ciência da linguagem. Tradução de Sheila Grillo e Ekaterina Vólkova Américo. São Paulo: Editora 34, 2018.

Recebido em: 08/04/2021

Aprovado em: 06/06/2021 